\title{
Landau Kleffner Syndrome and Misdiagnosis of Autism Spectrum Disorder: A Mini-Review
}

\author{
Ali Zafari' ${ }^{1}$, Nasim Karimi², Mahdi Taherian ${ }^{3}$, Reza Taherian ${ }^{1 *}$ \\ ${ }^{1}$ Student Research Committee, School of Medicine, Shahid Beheshti University of Medical Sciences, Tehran, \\ Iran \\ ${ }^{2}$ School of Nursing and Midwifery, Iran University of Medical Sciences, Tehran, Iran \\ ${ }^{3}$ Food and Drug Research Institute, Iran Food and Drug Administration, Ministry of Health and Medical \\ Education, Tehran, Iran
}

\begin{abstract}
Autism spectrum disorder (ASD) is the name for a group of developmental disorders including a wide range of signs, symptoms and disability. Landau Kleffner syndrome (LKS) or acquired epileptic aphasia is a pediatric disorder characterized by the association of epileptiform electroencephalographic (EEG) abnormalities and acquired aphasia. The early stages of the LKS may be manifested by the symptoms of the autism leading to misdiagnosis. Since LKS is a progressive disease, its misdiagnosis leads to a greater neurocognitive deterioration which may result in seizure in the final stages. The purpose of this review was to provide an overview of available researches on ASD population and patients with LKS and relationship between these 2 diseases.

Keywords: Landau-kleffner syndrome; Autism spectrum disorder; Speech/language disorders
\end{abstract}

\author{
*Correspondence to \\ Reza Taherian, MD; Student \\ Research Committee, School \\ of Medicine, Shahid Beheshti \\ University of Medical Sciences, \\ P.O.Box: 35147-65441, Tehran, \\ I. R. Iran. \\ Tel: +98(912)3314094; \\ Email: \\ Taherian.reza72@gmail.com
}

Published online March 15, 2018

Citation: Zafari A, Karimi N, Taherian M, Taherian R. Landau Kleffner syndrome and misdiagnosis of autism spectrum disorder: a minireview. Int Clin Neurosci J. 2018;5(1):3-6. doi: 10.15171/icnj.2018.02.

\section{Introduction}

Autism spectrum disorders (ASDs) and epileptic syndromes are heterogeneous disorders which are usually associated with other neurodevelopmental disorders such as intellectual disability and developmental delay. ${ }^{1}$ The association of ASDs and several epileptic syndromes has long been recognized. ${ }^{2}$ By recognizing overlapping molecular mechanism involved in both disorders, shared etiologic mechanism may be supposed. ${ }^{3}$ Among the epileptic syndromes, Landau Kleffner syndrome (LKS) is a less-studied disorder which is commonly associated with behavioral impairments including attentional problems and hyperactivity. ${ }^{4}$ This epileptic syndrome usually occurs between the ages of 3 and 10 (peak age 5-7 years) and is characterized by acquired auditory agnosia, loss of speech and epileptiform electroencephalographic (EEG) abnormalities in a child who was previously developmentally normal. ${ }^{5}$ Of note, children with a recently diagnosed ASD may also have experienced some early form of LKS, especially in 2 major groups: One, those with a prior episodes of regression accompanied with linguistic involvement and latter, those with the abnormal EEG findings. ${ }^{6-9}$ Hence, the current research aimed to review the main features of ASD and LKS to elucidate their similarities.

\section{Autism Spectrum Disorders}

ASDs include 2 main characteristics. The characteristics include the reduced social function of the patient, i.e. impaired communication and social behavior, and also restricted interests associated with repetition of special behaviors. ${ }^{10}$ ASD is highly prevalent, 14.7 per 1000 children ${ }^{11}$ and usually presents in children lower than three years old especially in infants. ${ }^{12}$ Although the child has no problem in saying the alphabet, they do not use words to communicate with others, e.g. their parents. ${ }^{12}$ This feature may be attributed to a delayed development in verbal skills by parents in early years, as the child grows, it becomes more obvious especially when they compare their children with other age-matched children. Some features of the disease can be helpful to identify children with ASD in early years; for instance, when they are happy, they do not seek out others, moreover, the do not call their parents by name or point to objects that are usually interesting in healthy children. In preschool years, the child repeats some specific behaviors such as bizarre hand or finger movement. As these children grow, their impairments fall into main measurable domains which will be usually consistent during the following years. ${ }^{12}$

Unfortunately, autism is a lifelong disorder; however, every patient with autism will benefit from therapies that

(C) 2018 The Author(s). This is an open access article distributed under the terms of the Creative Commons Attribution License (http:// creativecommons.org/licenses/by/4.0/), which permits unrestricted use, distribution, and reproduction in any medium, provided the original work is properly cited. 
can improve social function and abilities of them. Several treatment strategies such as neurofeedback training and speech therapy, psychoeducation therapy, assistive reading tools etc ${ }^{13}$ are suggested to enhance skills and abilities of children with ASD; however, no definitive modality can be considered for the treatment of this disorder.

\section{Landau Kleffner Syndrome}

Landau Kleffner syndrome (LKS) or acquired epileptic aphasia is a childhood disorder in which acquired aphasia and epileptiform EEG abnormalities are associated. Epileptic seizures are infrequent and not a prerequisite for LKS. Other clinical findings include cognitive impairment and global behavioral regression. ${ }^{7,14}$ Since the original report by Landau and Kleffner in 1957, several cases of this syndrome are reported. ${ }^{6}$ Commonly, LKS presents in children aged 2-8 years, with a peak between 5 and 7 years. The syndrome is more prevalent in in boys compared to girls. Moreover, the age of onset may be as early as $18-22$ months and as late as $13-14$ years. ${ }^{15}$ The most prominent characteristic of this syndrome is an acquired aphasia. This type of aphasia can be described as a verbal auditory agnosia, which is the failure to give a semantic significance to the different sounds. ${ }^{16}$ The loss of receptive language is followed by expressive aphasia, with a significant reduction in spontaneous speech. The onset of aphasia is subacute and its course is progressive with a fluctuating pattern of spontaneous improvements and exacerbations. The most commonly observed behavioral problems include impulsivity, distractibility, hyperactivity and attentional deficits. ${ }^{17}$ As described by William Landau and Frank Kleffner in 1957, 6 kids who were presented to their institute with the history of recent hearing loss, were evaluated with the possible diagnosis of acquired hearing loss and its differential diagnosis. ${ }^{7}$ The disorder began with verbal auditory agnosia and the children behaved as if he/she was deaf. As the disease progressed, loss of expressive speech was added to other manifestations. The verbal and intellectual assessments showed normal hearing and near to normal non-verbal perception. An interesting finding on EEG of these children was quite dramatic changes in their prominent centrotemporal spikes and widely spreading sharp waves over both hemispheres. All the patients in their investigation had a history of seizures immediately after failure in verbal skills. ${ }^{7}$ Finally, the syndrome named LKS, although there were other conditions with the same characteristics such as EEG abnormalities or epileptic encephalopathy. ${ }^{14}$ Hence, a high index of suspicion can raise the need for EEG studies especially in older children, who are presented with seizures and progressive verbal intelligence. ${ }^{18}$ Numerous studies have been done to investigate if there is correlation between LKS and the dysfunction in that of patient short term memory (STM) ${ }^{19}$ Besides, auditory system may still be impaired in some processes, while the child has recovered from LKS even in presence of normal EEG and language. ${ }^{20} \mathrm{~A}$ study about phonological short term memory by repetition of single words was not different among the groups; however, repetition of word sequences was performed significantly below controls in the LKS group. ${ }^{19}$ Bilateral decrease in posterior superior temporal gyrus metabolism was found in children with lower scores. Somewhat poorer scores in repeating word sequences, than single words, can suggest discrepancy of phonological STM in addition to deficit in the identification of phonemes. ${ }^{18}$ Based on recent studies a normal EEG should be present for the language improvement in these patients while it may not be enough. One of the most robust predictor of outcome, proved by these studies, is the duration of prolonged EEG epileptiform abnormalities (i.e., electrical status epilepticus in sleep). ${ }^{14,18}$

\section{Landau Kleffner Syndrome and Autism Spectrum Disorders}

It is now generally accepted that LKS accounts for one severe end of the continuum of cognitive manifestations which is observed in idiopathic focal epilepsy of pediatrics. ${ }^{22}$ LKS may cause prolonged and severe loss of linguistic ability due to its impact on language areas. However, it became widely recognized when pediatric neurologists and psychiatrists realized the fact that there is a high percentage of the autism children might have a language and social deterioration in their past medical history. Meanwhile some children had seizures and some other had just electroencephalogram wave turbulence, especially during sleep. ${ }^{23}$ Here is a notion that epileptic activities might be linked to autism. Also, a suppression in brain electrical activities, might improve or even cure autism. Hence, investigators should obtain EEG recordings in all recently known cases of the disease to distinguish between those who need antiepileptic treatment and those who do not need therapy. ${ }^{24}$ Later studies reported that children with autism and a positive history of regression do not have a significantly higher rate of abnormalities in EEG abnormalities compared to those who did not regress. ${ }^{25,26}$ On the other hand, sleep EEG studies study on large series of children with autistic behavior is now under investigation. ${ }^{27}$ Pediatric psychiatrists who have visited many children diagnosed with autism and a history of regression report that children with one episode of regression almost had only very few words to use (no more than 10) before losing them. ${ }^{28}$ Here is a point; loss of word and lack of language is more and more remarkable than the loss of social skills related to language, even if these skills starts prior to word loss. ${ }^{29}$ Many children with primary diagnosis of autism, finally diagnosed as early LKS. The disease identification and final diagnosis is based on clinical judgments, EEG results, symptoms fluctuations and recurrences and there is a little place on a detailed analysis of both the linguistic and behavioral symptoms 
and their progression..$^{30,31}$ Autism behavior might be a reflective of language loss in these patients or even could be a result of developmental deficit following the epileptic activities which involves both language and "social brain". Finally, a favorable response to an EEG suppression or remission and improvement periods in the language, could be considered as a proof for those whom diagnosis is early form LKS. ${ }^{32}$

\section{Conclusion}

Because of the case reports of children with early-onset seizures and autistic regression, parallels have been drawn between children with "autistic regression" and LandauKleffner syndrome. ${ }^{33-35}$ There is no quantifiable definition of autistic regression, and there continues to be debate in the field regarding its true prevalence, as it is rather a descriptive term that refers to children who seem to lose skills in language and social communication and who develop a repetitive and restrictive pattern of interests and behaviors consistent with the diagnosis of ASD. ${ }^{36}$ There are 3 major differences between children with autistic regression and those with an epileptic encephalopathy such as LKS. The first is age of onset. The second difference lies in the behavioral profiles. Lastly, there are differences in the EEG finding. ${ }^{36}$ Despite studies showing that the prevalence of epileptic disorders in individuals with ASD and no history of seizure or epilepsy range from $6 \%$ to $60 \%$, significant controversy remains about the specificity of these findings to the ASD phenotype, with or without regression. ${ }^{27,37-40}$ In addition to formerly discussed studies, some other showing that antiepileptic medications can have a positive impact on behavior, ${ }^{38,41}$ and no studies have yet demonstrated that treatment of epileptic disorders positively impact social, language, cognitive, or behavioral outcomes. ${ }^{6,26-37}$

\section{Conflict of Interest Disclosures}

The authors declare that they have no conflict of interests.

\section{Ethical Statement}

Not applicable.

\section{Acknowledgements}

This study is related to the project NO 1395/77498 from Student Research Committee, Shahid Beheshti University of Medical Sciences, Tehran, Iran. We also appreciate the "Student Research Committee" and "Research \& Technology Chancellor" in Shahid Beheshti University of Medical Sciences for their financial support of this study.

\section{References}

1. Salpekar JA, Mishra G. Key issues in addressing the comorbidity of attention deficit hyperactivity disorder and pediatric epilepsy. Epilepsy Behav. 2014;37:310-5. doi: 10.1016/j. yebeh.2014.04.021.

2. Deykin EY, MacMahon B. The incidence of seizures among children with autistic symptoms. Am J Psychiatry. 1979;136(10):1310-2. doi: 10.1176/ajp.136.10.1310.

3. Brooks-Kayal A. Epilepsy and autism spectrum disorders: are there common developmental mechanisms? Brain Dev. 2010;32(9):731-8. doi: 10.1016/j.braindev.2010.04.010.

4. Stefanatos G. Changing perspectives on Landau-Kleffner syndrome. Clin Neuropsychol. 2011;25(6):963-88. doi: 10.1080/13854046.2011.614779.

5. Fandino M, Connolly M, Usher L, Palm S, Kozak FK. LandauKleffner syndrome: a rare auditory processing disorder series of cases and review of the literature. Int J Pediatr Otorhinolaryngol. 2011;75(1):33-8. doi: 10.1016/j.ijporl.2010.10.001.

6. Deonna T, Roulet-Perez E. Early-onset acquired epileptic aphasia (Landau-Kleffner syndrome, LKS) and regressive autistic disorders with epileptic EEG abnormalities: the continuing debate. Brain Dev. 2010;32(9):746-52. doi: 10.1016/j. braindev.2010.06.011.

7. Landau WM, Kleffner FR. Syndrome of acquired aphasia with convulsive disorder in children. 1957. Neurology. 1998;51(5):1241, 8 pages following

8. Ballaban-Gil K, Tuchman R. Epilepsy and epileptiform EEG: association with autism and language disorders. Ment Retard Dev Disabil Res Rev. 2000;6(4):300-8. doi: 10.1002/1098-2779(2000)6:4<300::aid-mrdd9>3.0.co;2-r.

9. Oslejskova H, Dusek L, Makovska Z, Pejcochova J, Autrata $\mathrm{R}$, Slapak I. Complicated relationship between autism with regression and epilepsy. Neuro Endocrinol Lett. 2008;29(4):55870.

10. American Psychiatric Association. Diagnostic and Statistical Manual of Mental Disorders. Washington, DC: American Psychiatric Association; 1994.

11. Prevalence of autism spectrum disorder among children aged 8 years - autism and developmental disabilities monitoring network, 11 sites, United States, 2010. MMWR Surveill Summ. 2014;63(2):1-21.

12. Lord C, Cook EH, Leventhal BL, Amaral DG. Autism spectrum disorders. Neuron. 2000;28(2):355-63.

13. Binnie CD. Cognitive impairment during epileptiform discharges: is it ever justifiable to treat the EEG? Lancet Neurol. 2003;2(12):725-30.

14. Caraballo RH, Cejas N, Chamorro N, Kaltenmeier MC, Fortini S, Soprano AM. Landau-Kleffner syndrome: a study of 29 patients. Seizure. 2014;23(2):98-104. doi: 10.1016/j. seizure.2013.09.016.

15. Tassinari CA, Cantalupo G, Dalla Bernardina B, Darra F, Bureau M, Cirelli C, et al. Encephalopathy related to status epilepticus during slow sleep (ESES) including Landau-Kleffner syndrome. In: Epileptic syndromes in infancy, childhood and adolescence. John Libbey Eurotext; 2012:255-75.

16. Soprano A, Garcia E, Caraballo R, Fejerman N. Neuropsychologic and neurolinguistic aspects in acquired epileptic aphasia (AEA) or Landau-Klefener syndrome. Pediatr Neurol. 1992;8(5):398-9.

17. Robinson RO, Baird G, Robinson G, Simonoff E. LandauKleffner syndrome: course and correlates with outcome. Dev Med Child Neurol. 2001;43(4):243-7.

18. Titus JB. Neuropsychological assessment of children with Landau-Kleffner syndrome. J Pediatr Epilepsy. 2017;6(1):62-8. doi: 10.1055/s-0036-1585061.

19. Majerus S, Laureys S, Collette F, Del Fiore G, Degueldre C, Luxen A, et al. Phonological short-term memory networks following recovery from Landau and Kleffner syndrome. Hum Brain Mapp. 2003;19(3):133-44. doi: 10.1002/hbm.10113.

20. Metz-Lutz MN, Hirsch E, Maquet P, de Saint Martin A, Rudolf G, Wioland $\mathrm{N}$, et al. Dichotic listening performances in the followup of Landau and Kleffner syndrome. Child Neuropsychol. 1997;3(1):47-60. doi: 10.1080/09297049708401367.

21. Cockerell I, Bolling G, Nakken KO. Landau-Kleffner syndrome in Norway: long-term prognosis and experiences with the health services and educational systems. Epilepsy Behav. 
2011;21(2):153-9. doi: 10.1016/j.yebeh.2011.03.019.

22. Saltik S, Uluduz D, Cokar O, DemirbilekV, Dervent A. A clinical and EEG study on idiopathic partial epilepsies with evolution into ESES spectrum disorders. Epilepsia. 2005;46(4):524-33. doi: 10.1111/j.0013-9580.2005.45004.x.

23. Lord C, Shulman C, DiLavore P. Regression and word loss in autistic spectrum disorders. J Child Psychol Psychiatry. 2004;45(5):936-55. doi: 10.1111/j.1469-7610.2004.t01-100287.x.

24. Chez MG, Chang M, Krasne V, Coughlan C, Kominsky M, Schwartz A. Frequency of epileptiform EEG abnormalities in a sequential screening of autistic patients with no known clinical epilepsy from 1996 to 2005. Epilepsy Behav. 2006;8(1):267-71. doi: 10.1016/j.yebeh.2005.11.001.

25. Tuchman RF, Rapin I. Regression in pervasive developmental disorders: seizures and epileptiform electroencephalogram correlates. Pediatrics. 1997;99(4):560-6.

26. Baird G, Robinson RO, Boyd S, Charman T. Sleep electroencephalograms in young children with autism with and without regression. Dev Med Child Neurol. 2006;48(7):604-8. doi: 10.1017/s0012162206001265.

27. Chez MG, Chang M, Krasne V, Coughlan C, Kominsky M, Schwartz A. Frequency of epileptiform EEG abnormalities in a sequential screening of autistic patients with no known clinical epilepsy from 1996 to 2005. Epilepsy Behav. 2006;8(1):267-71. doi: 10.1016/j.yebeh.2005.11.001.

28. Bock G, Goode J. Autism: Neural Basis and Treatment Possibilities. John Wiley \& Sons; 2003.

29. Deonna T, Roulet-Perez E. Early-onset acquired epileptic aphasia (Landau-Kleffner syndrome, LKS) and regressive autistic disorders with epileptic EEG abnormalities: the continuing debate. Brain Dev. 2010;32(9):746-52. doi: 10.1016/j. braindev.2010.06.011.

30. Uldall P, Sahlholdt L, Alving J. Landau-Kleffner syndrome with onset at 18 months and an initial diagnosis of pervasive developmental disorder. Eur J Paediatr Neurol. 2000;4(2):81-6. doi: 10.1053/ejpn.2000.0268.
31. Ribeiro KM, Assumpcao FB, Jr., Valente KD. [Landau-Kleffner and autistic regression: the importance of differential diagnosis]. Arq Neuropsiquiatr. 2002;60(3-b):835-9.

32. Besag FM. Cognitive and Behavioural Disorders of Epileptic Origin in Children. Clinics in Developmental Medicine No. 168. Dev Med Child Neurol. 2007;49(5):400.

33. Deonna T, Roulet-Perez E, Chappuis H, Ziegler AL. 'Autistic regression associated with seizure onset in an infant with tuberous sclerosis'. Dev Med Child Neurol. 2007;49(4):320.

34. Neville BG, Harkness WF, Cross JH, Cass HC, Burch VC, Lees JA, et al. Surgical treatment of severe autistic regression in childhood epilepsy. Pediatr Neurol. 1997;16(2):137-40.

35. Tuchman R. CSWS-related autistic regression versus autistic regression without CSWS. Epilepsia. 2009;50 Suppl 7:18-20. doi: 10.1111/j.1528-1167.2009.02212.x.

36. Jeste SS, Tuchman R. Autism Spectrum Disorder and Epilepsy: Two Sides of the Same Coin? J Child Neurol. 2015;30(14):196371. doi: $10.1177 / 0883073815601501$.

37. Kagan-Kushnir T, Roberts SW, Snead OC, 3rd. Screening electroencephalograms in autism spectrum disorders: evidence-based guideline. J Child Neurol. 2005;20(3):197206. doi: $10.1177 / 08830738050200030601$.

38. Tuchman R. AEDs and psychotropic drugs in children with autism and epilepsy. Ment Retard Dev Disabil Res Rev. 2004;10(2):135-8. doi: 10.1002/mrdd.20026.

39. Tharp BR. Epileptic encephalopathies and their relationship to developmental disorders: do spikes cause autism? Ment Retard Dev Disabil Res Rev. 2004;10(2):132-4. doi: 10.1002/ mrdd. 20025.

40. Tuchman R, Alessandri M, Cuccaro M. Autism spectrum disorders and epilepsy: moving towards a comprehensive approach to treatment. Brain Dev. 2010;32(9):719-30. doi: 10.1016/j.braindev.2010.05.007.

41. Di Martino A, Tuchman RF. Antiepileptic drugs: affective use in autism spectrum disorders. Pediatr Neurol. 2001;25(3):199207. 